\title{
DISEÑO Y VALIDACIÓN DE UN CUESTIONARIO DIRIGIDO A DESCRIBIR LA EVALUACIÓN EN PROCESOS DE EDUCACIÓN A DISTANCIA
}

\author{
DESIGN AND VALIDATION OF A QUESTIONNAIRE AIMED TO DESCRIBE \\ ASSESSMENT IN DISTANCE EDUCATION PROCESSES
}

\author{
Esther García López; ebuisan@unimet.edu.ve \\ Universidad Metropolitana (Venezuela) \\ Julio Cabero Almenara; cabero@us.es \\ Universidad de Sevilla (España-UE)
}

\begin{abstract}
RESUMEN
El presente trabajo expone los pasos seguidos para el diseño y la validación mediante juicio de expertos de un cuestionario dirigido a describir, desde la perspectiva del docente, la evaluación en procesos de educación a distancia. Tratándose de un instrumento de elaboración propia, necesariamente debía ser validado mediante algún procedimiento metodológicamente adecuado, por lo que se sometió a validación de contenido por expertos en tres dimensiones clave. Todas las respuestas y sugerencias fueron procesadas, analizadas y consideradas para la construcción de la versión final de un cuestionario útil para su propósito y con validez científica.
\end{abstract}

PALABRAS CLAVE: Evaluación, educación a distancia, diseño de cuestionarios, validación por juicio de expertos.

\section{ABSTRACT}

This paper presents the steps followed to design and validate by expert opinion a questionnaire aimed to describe, from the teachers' perspective, assessment in distance learning processes. Being a home-made instrument, it had to be validated by a methodologically sound procedure, so it was subjected to content validation by experts in three key dimensions. All responses and suggestions were processed, analyzed and considered for the construction of the final version of a questionnaire useful for its purpose and scientifically valid. 
KEYWORDS: Assessment, distance education, questionnaire design, validation by expert opinion.

\section{INTRODUCCIÓN}

El proceso de diseño y validación que se expone seguidamente fue parte esencial de un trabajo de investigación cuyo propósito era describir la evaluación en las acciones educativas a distancia de la Universidad Metropolitana, en Caracas, Venezuela. Uno de los objetivos específicos del estudio era "describir los procesos de evaluación bajo estas modalidades, desde la perspectiva del docente" y para lograrlo se decidió aplicar un cuestionario que proporcionara los datos necesarios para describir las prácticas evaluativas que realmente se llevaron a cabo en las asignaturas previamente identificadas como población.

Así, para recoger estos datos se tomaron las siguientes acciones:

- Selección de la técnica de recolección de datos: Cuestionario.

- Identificación de la fuente de los datos: Profesores que impartieron las asignaturas que conformaban la población.

- Determinación del objetivo del cuestionario: Recoger los datos necesarios para describir, desde la perspectiva del docente, los procesos de evaluación que se desarrollaron en las acciones educativas a distancia de la Universidad Metropolitana, en Caracas, Venezuela.

- Diseño, formulación y revisión interna de la primera versión del instrumento: Con base en una revisión previa de la literatura se construyeron preguntas con respuestas cerradas, categorizadas y abiertas, para recoger datos tanto cuantitativos como cualitativos.

Esta técnica [el cuestionario] es de carácter cuantitativo, obtenemos datos numéricos como pueden ser los porcentajes, pero si queremos utilizar esta técnica en una investigación de carácter descriptivo, podemos transformar este instrumento en cualitativo sin dejar de ser cuantitativo, con algunos ítems abiertos que se pueden responder. (Sánchez, 2003: 258)

Adicionalmente, siguiendo las clasificaciones propuestas por Buendía (1998: 209-211), se incluyeron preguntas de identificación, de acción, de contenido, de información y de opinión, así como algunas que actuaran como filtro. La tabla 1 muestra el diseño elaborado durante la etapa de formulación de la versión inicial del instrumento. Como producto de esta etapa se obtuvo el cuestionario que posteriormente se envió a los expertos para la validación de su contenido. 


\begin{tabular}{|c|c|c|c|}
\hline \multicolumn{4}{|l|}{ Dimensión I: Perfil del docente. } \\
\hline Indicadores & Preguntas & Naturaleza & Respuesta \\
\hline I.1.1. Dedicación docente en la Unimet & 1 & $\begin{array}{c}\text { Identificació } \\
\mathrm{n}\end{array}$ & Categorizada \\
\hline I.1.2. Antigüedad en la Unimet & 1 & $\begin{array}{c}\text { Identificació } \\
\mathrm{n}\end{array}$ & Categorizada \\
\hline I.2.1. Antigüedad impartiendo la asignatura & 1 & $\begin{array}{c}\text { Identificació } \\
\mathrm{n}\end{array}$ & Categorizada \\
\hline I.3.1. Formación en el modelo AcAd & 1 & Acción & Cerrada \\
\hline $\begin{array}{l}\text { I.3.2. Formación en el diseño instruccional } \\
\text { DIUM }\end{array}$ & 1 & Acción & Cerrada \\
\hline I.3.3. Formación en la plataforma PI@tum & 1 & Acción & Cerrada \\
\hline $\begin{array}{l}\text { l.4.1. Formación en evaluación de } \\
\text { aprendizajes }\end{array}$ & 1 & $\begin{array}{l}\text { Acción y } \\
\text { filtro }\end{array}$ & Cerrada \\
\hline I.4.2. Mecanismos de formación & 1 & Acción & Categorizada \\
\hline \multicolumn{4}{|l|}{ Dimensión II: Perfil de la asignatura. } \\
\hline II.1.1. Modalidad en que se imparte & 1 & Contenido & Categorizada \\
\hline II.2.1. Naturaleza de la asignatura & 1 & Opinión & Mixta \\
\hline \multicolumn{4}{|l|}{ Dimensión III: Características de la evaluación. } \\
\hline $\begin{array}{l}\text { III.1.1. Concepto de evaluación de } \\
\text { aprendizajes }\end{array}$ & 1 & Información & Abierta \\
\hline $\begin{array}{l}\text { III.1.2. Factores que caracterizan a la } \\
\text { evaluación }\end{array}$ & 1 & $\begin{array}{l}\text { Información } \\
\text { y opinión }\end{array}$ & Mixta \\
\hline $\begin{array}{l}\text { III.2.1. Tipos que aplica según el momento y } \\
\text { la } \\
\text { frecuencia }\end{array}$ & 2 & Contenido & $\begin{array}{c}\text { Categorizada } \\
\mathrm{s}\end{array}$ \\
\hline $\begin{array}{l}\text { III.2.2. Método que aplica según los agentes } \\
\text { evaluadores }\end{array}$ & 2 & Contenido & $\begin{array}{c}1 \text { mixta } \\
1 \\
\text { categorizada }\end{array}$ \\
\hline III.2.3. Modalidad de aplicación & 1 & Contenido & Categorizada \\
\hline III.3.1. Instrumentos aplicados & 1 & Contenido & Mixta \\
\hline III.4.1. Frecuencia de retroalimentación & 1 & Contenido & Categorizada \\
\hline $\begin{array}{l}\text { III.5.1. Fortalezas y debilidades de la } \\
\text { evaluación } \\
\text { aplicada }\end{array}$ & 2 & Opinión & Abiertas \\
\hline
\end{tabular}

Tabla 1: Diseño inicial del cuestionario

\section{MÉTODO}

El cuestionario es uno de los instrumentos tradicionales utilizados en la investigación en el terreno de la Tecnología Educativa (Barroso y Cabero, 2010), realizándose con él investigaciones en una diversidad de problemáticas, como por ejemplo son: la integración de los medios en los centros (Lorenzo y Trujillo, 2008), percepciones sobre las plataformas de $e$ learning (Blázquez y Alonso, 2009; Muñoz y González, 2010), incorporación de tecnologías específicas en los centros (Aguaded y Tirado, 2010), diseño de cursos virtuales (Granda, 2010) o las competencias tecnológicas de los profesores (Fernández y otros, 2011). 
En nuestro caso fue producto de elaboración propia, por lo que necesariamente debía ser validado mediante algún procedimiento metodológicamente adecuado. Así, el instrumento fue sometido a un proceso de validación de contenido mediante juicio de expertos, procedimiento usualmente utilizado para este tipo de acciones (Barroso y Cabero, 2010). Según Ruiz (2002: 75) "A través de la validez de contenido se trata de determinar hasta dónde los ítemes de un instrumento son representativos del dominio o universo de contenido de la propiedad que se desea medir" y en cuanto al procedimiento asegura:

A diferencia de otros tipos de validez, la de contenido no puede ser expresada cuantitativamente, a través de un índice o coeficiente; ella es más bien una cuestión de juicio. Es decir, la validez de contenido, por lo general, se estima de manera subjetiva o intersubjetiva. El procedimiento más comúnmente empleado para determinar este tipo de validez, es el que se conoce con el nombre de juicios de expertos... (Ruiz, 2002: 76).

Para este proceso se establecieron tres dimensiones que representaban las áreas de conocimiento en las que se inscribía la investigación, a saber: Evaluación educativa (20 expertos), educación a distancia (16 expertos) y aprendizaje en línea o e-learning (9 expertos). Puesto que esta técnica para la validación de los cuestionarios presenta le problema de que le concepto de "experto" es bastante polisémico. Prestamos especial atención en su elección, y de esta forma se adoptó la decisión de que el hilo conductor para la selección de los especialistas fue que presentaran, por un lado, experticias comunes necesarias para evaluar la adecuación del contenido del instrumento $y$, por el otro, experticias diversas cuya complementariedad favoreciera la valoración desde perspectivas variadas.

Así, la formación académica de cada experto fue considerada como criterio de importancia para su incorporación al grupo evaluador, acompañada por el desarrollo y difusión de trabajos en el área correspondiente, tanto en el ámbito académico, como en el profesional y en el de la investigación. También se consideró que los expertos desarrollaran sus labores en diferentes países, a fin de incorporar las diversas perspectivas que surgen de la experiencia en contextos con características, culturas e idiosincrasias variadas. En consecuencia, se invitaron expertos de Uruguay, México, Puerto Rico, Ecuador, Argentina, Chile, Colombia, Cuba, Brasil, España y Venezuela.

Se hizo llegar a los cuarenta y cinco expertos tanto el cuestionario como la guía para su validación. Cinco expertos en el área de evaluación educativa, tres en el área de e-learning y dos en educación a distancia aceptaron participar en el proceso, conformándose así un grupo de 10 especialistas que combinaba los conocimientos necesarios para una valoración experta del contenido del cuestionario.

\subsection{Diseño de la guía de validación.}

La guía se estructuró en cuatro partes: las primeras tres recogían las valoraciones de los expertos con respecto a los elementos que conformaban el cuestionario (carta de presentación, instrucciones para el proceso de respuesta y preguntas), mientras que la última parte consultaba su apreciación sobre la validez de contenido del instrumento en general. Siguiendo las clasificaciones propuestas por Buendía (1998: 209-211), la guía se construyó con 15 ítemes de opinión con respuestas categorizadas. Para expresar sus juicios los expertos contaron con cuatro categorías de respuesta: Excelente, Buena, Regular y Mala. Adicionalmente las cuatro partes ofrecían espacios para que cada experto escribiera abiertamente las modificaciones que considerara necesarias y también se incluyeron áreas para que expresara libremente preguntas que debieran incorporarse, su percepción general 
sobre el cuestionario y sus observaciones o recomendaciones. La versión definitiva de la guía puede verse en el Anexo 1.

Señalar que en todo momento se tuvieron en cuenta las recomendaciones que Lukas y Santiago (2004) y Albert (2006), nos proponen para su puesta en acción.

\subsection{Modalidad de aplicación de la guía de validación.}

La separación física entre el investigador y los expertos llevó a seleccionar el correo electrónico como la vía de intercambio idónea para el proceso de validación. La guía y el cuestionario a evaluar se enviaron a cada experto solicitándole la devolución de sus valoraciones por el mismo medio.

\section{RESULTADOS}

A continuación se presentan los resultados agrupados según las partes que componen la guía de valoración, a saber: Carta de presentación, instrucciones para el proceso de respuesta, preguntas del cuestionario y valoración general del cuestionario. En cada parte se exponen tanto los resultados cuantitativos como los cualitativos.

\section{Parte I. Carta de presentación.}

Los resultados cuantitativos de la validación de la carta de presentación pueden verse consolidados en la gráfica 1. En ella se evidencia que, salvo un único caso, todas las valoraciones se ubicaron en las categorías Buena o Excelente, con predominancia de la primera.

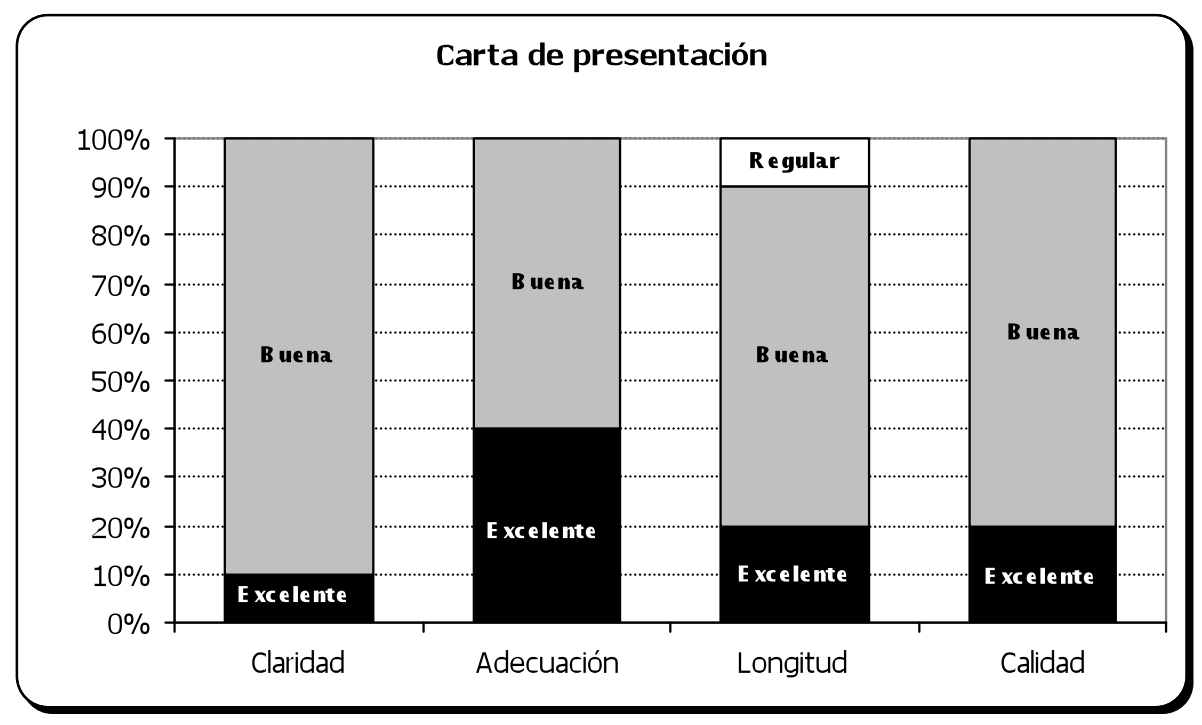

Gráfica 1: Resultados cuantitativos de la validación por juicio de expertos de la carta de presentación.

El experto que consideró Regular la longitud del texto no aclaró el motivo de su calificación y, por el contrario, expresó en la pregunta abierta correspondiente: "Respecto de la carta a la cual se refiere propiamente esta pregunta, no tengo comentarios específicos" (Experto 10), por lo que no se introdujeron cambios en relación directa con esta valoración.

Asumiendo que las cuatro variables tienen igual peso en la validación del contenido de la carta de presentación, las valoraciones generaron las siguientes medidas de tendencia 
central: $\bar{x}=3,2$ (entre Buena $=3$ y Excelente $=4$ ) con $S(x)=0,4641 ; M_{e}=3,0$ (Buena) y $M_{d}=$ 3,0 (Buena).

De acuerdo con estos resultados, los expertos consideraron que la carta de presentación era buena en cuanto a la claridad de sus planteamientos, su adecuación a los destinatarios, la longitud del texto y la calidad de su contenido. Sin embargo, $60 \%(f=6)$ de ellos sugirieron cambios en sus respuestas a la pregunta abierta: "Modificaciones que haría a la carta de presentación". El análisis de los cambios sugeridos por los expertos arrojó tres categorías bajo las cuales pueden agruparse: Contenido, estructura y uso del lenguaje. A continuación se presenta un ejemplo de cada categoría.

- Contenido: Indicar que la participación es voluntaria (Experto 2).

- Estructura: Fusionar el segundo párrafo con el último (Experto 4).

- Uso del lenguaje: Ajustar la redacción de los párrafos 4 y 5 (Experto 6).

Parte II. Instrucciones para el proceso de respuesta.

Los resultados cuantitativos de la validación de las instrucciones para el proceso de respuesta pueden verse consolidados en la gráfica 2. En ella se evidencia que en todos los casos al menos el $80 \%$ de las valoraciones se ubicaron en las categorías Buena o Excelente. Los dos expertos que emitieron valoraciones en la categoría Regular y el que no respondió, expresaron en las preguntas abiertas los cambios que consideraron pertinentes y ellos se analizaron para su incorporación al instrumento.

Asumiendo que las cuatro variables tienen igual peso en la validación del contenido de las instrucciones para el proceso de respuesta, las valoraciones generaron las siguientes medidas de tendencia central: $\bar{x}=3,359$ (entre Buena $=3$ y Excelente $=4$ ) con $S(x)=0,5843$; $M_{e}=3,0$ (Buena) y $M_{d}=3,0$ (Buena).

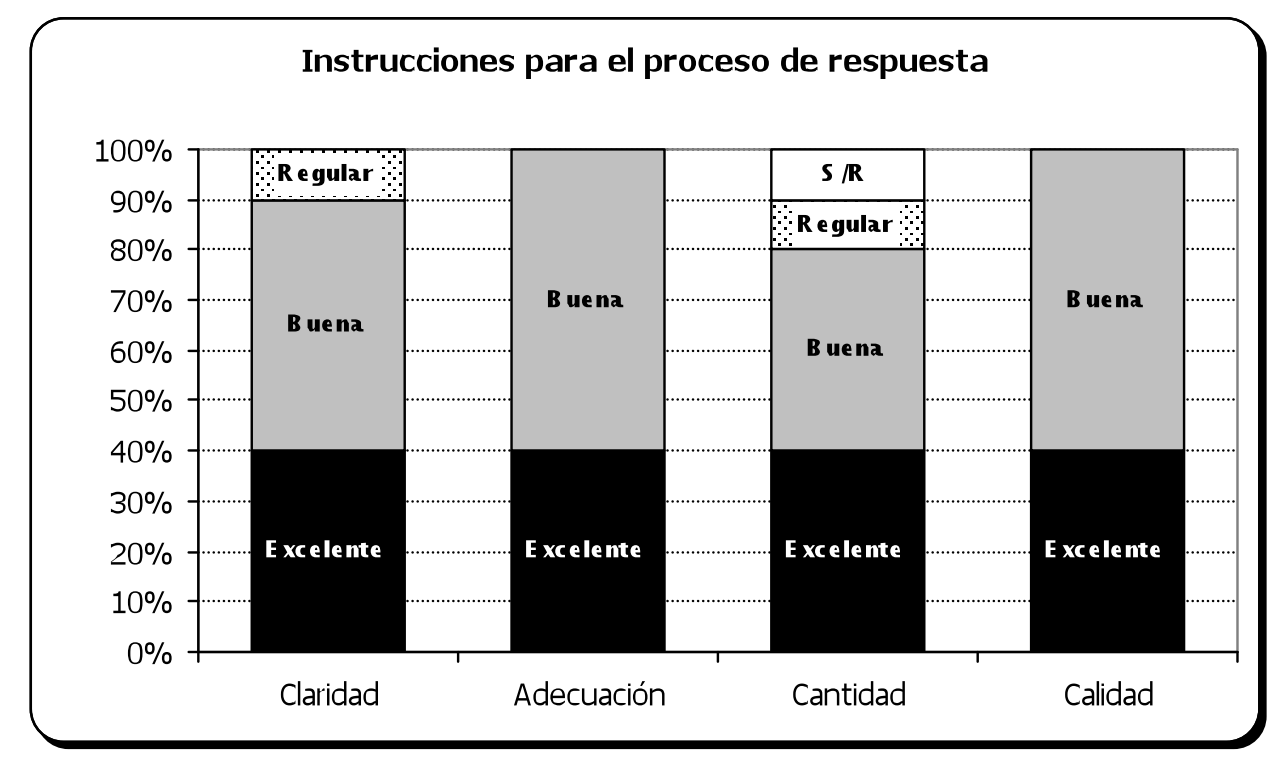

Gráfica 2: Resultados cuantitativos de la validación por juicio de expertos de las instrucciones para el proceso de respuesta.

De acuerdo con estos resultados, los expertos consideraron que las instrucciones para el proceso de respuesta eran buenas en cuanto a su calidad, su adecuación, su cantidad y su calidad. Sin embargo, $40 \%(\mathrm{f}=4)$ de ellos sugirieron cambios a través de la pregunta abierta "Modificaciones que haría a las instrucciones". Debido a la diversidad de formatos que 
presentan los reactivos, a que "...cada reactivo, según su formato, tiene instrucciones propias" (Experto 2) y a la naturaleza de las respuestas de los expertos, las sugerencias relacionadas con las instrucciones se agruparon de acuerdo con las preguntas del cuestionario evaluado. A continuación se presentan algunos ejemplos.

- En las instrucciones de la Parte I (Perfil del docente): Cambiar "...exprese la situación actual” por “...exprese su situación actual” (Expertos 8 y 9).

- En las instrucciones de la pregunta 11: Cambiar la palabra "concepto" por el término "definición" (Experto 9).

Parte III. Preguntas del cuestionario.

Los resultados cuantitativos de la validación de las preguntas pueden verse consolidados en la gráfica 3. En ella se evidencia que en todos los casos al menos el $90 \%$ de las valoraciones se ubicaron en las categorías Buena o Excelente.

Asumiendo que las seis variables tienen igual peso en la validación del contenido de las preguntas del cuestionario, las valoraciones generaron las siguientes medidas de tendencia central: $\bar{x}=3,3833$ (entre Buena $=3$ y Excelente $=4$ ) con $S(x)=0,5552 ; M_{e}=3,0$ (Buena) y $M_{d}=3,0$ (Buena).

De acuerdo con estos resultados, los expertos consideraron que las preguntas del cuestionario eran buenas en cuanto al orden lógico de su presentación, la claridad en su redacción, la adecuación de sus opciones de respuesta, su cantidad, su adecuación a los destinatarios y su eficacia para proporcionar los datos requeridos. Sin embargo, $60 \%(f=6)$ de ellos sugirieron cambios en las preguntas del cuestionario a través de sus respuestas a la pregunta abierta "Modificaciones que haría a las preguntas" y $50 \%(f=5)$ sugirió preguntas o temas de indagación adicionales a través de la pregunta abierta "Preguntas que agregaría".

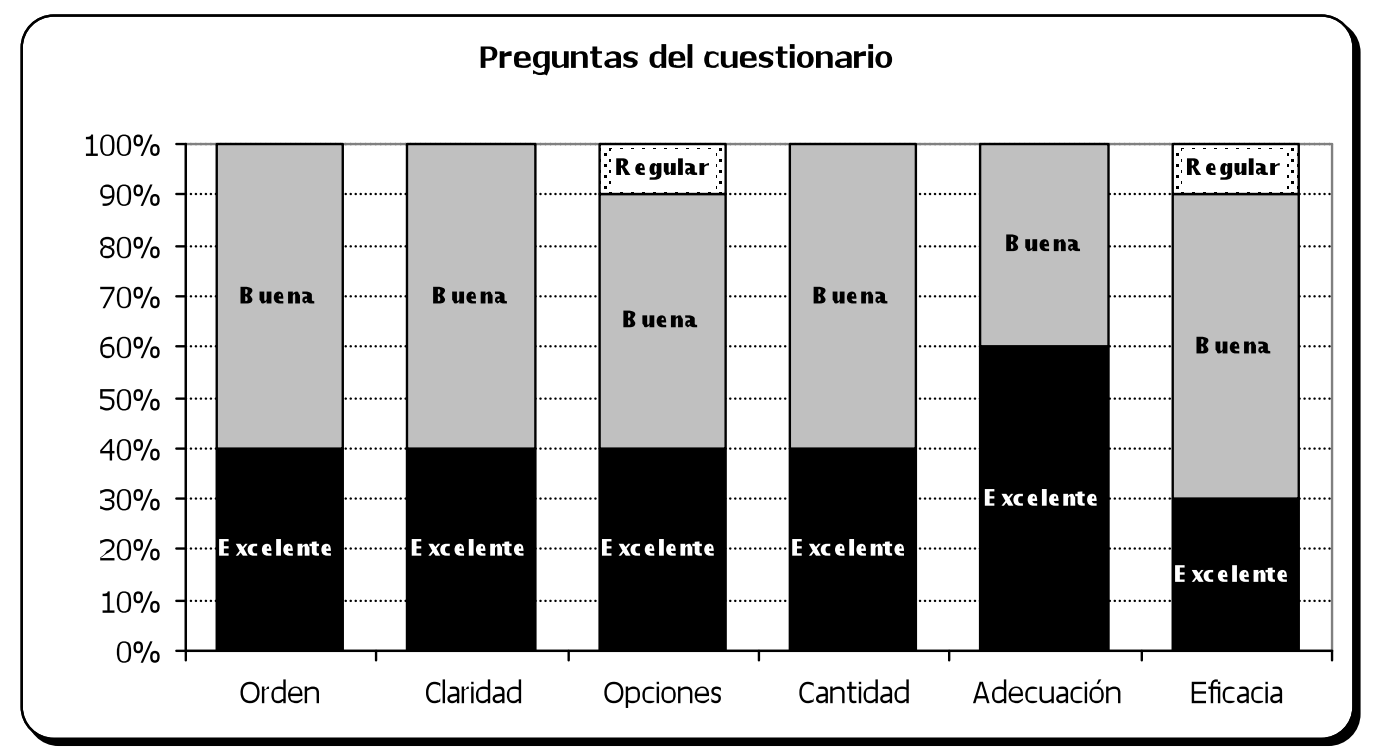

Gráfica 3: Resultados cuantitativos de la validación por juicio de expertos de las preguntas del cuestionario.

A continuación se presentan algunos ejemplos de cambios recomendados para las preguntas existentes e interrogantes que los expertos añadirían. 
1. Modificaciones sugeridas.

- Pregunta 7: Reformularla ajustándola a la categoría que parece dominar en el grupo de preguntas anteriores (Experto 6).

- Pregunta 18: Agregar la opción Rúbrica (Experto 3).

2. Preguntas que agregarían los expertos.

- En la Parte I (Perfil del docente): Solicitar información adicional sobre categoría académica y nivel de formación del profesor (Expertos 3 y 4 ).

- En la Parte II (Perfil de la asignatura): Preguntar si la asignatura es obligatoria u optativa (Experto 5).

- En la Parte III (Características de la evaluación): Referencia a la autoevaluación, por considerarse decisiva (Experto 1).

Parte IV. Valoración general del cuestionario.

Los resultados cuantitativos de la validación general del cuestionario pueden verse en la gráfica 4. En ella se evidencia que el $20 \%(f=2)$ de los expertos otorgó la valoración Excelente a la validez general de contenido del cuestionario y el $80 \%(f=8)$ de ellos la consideró Buena.

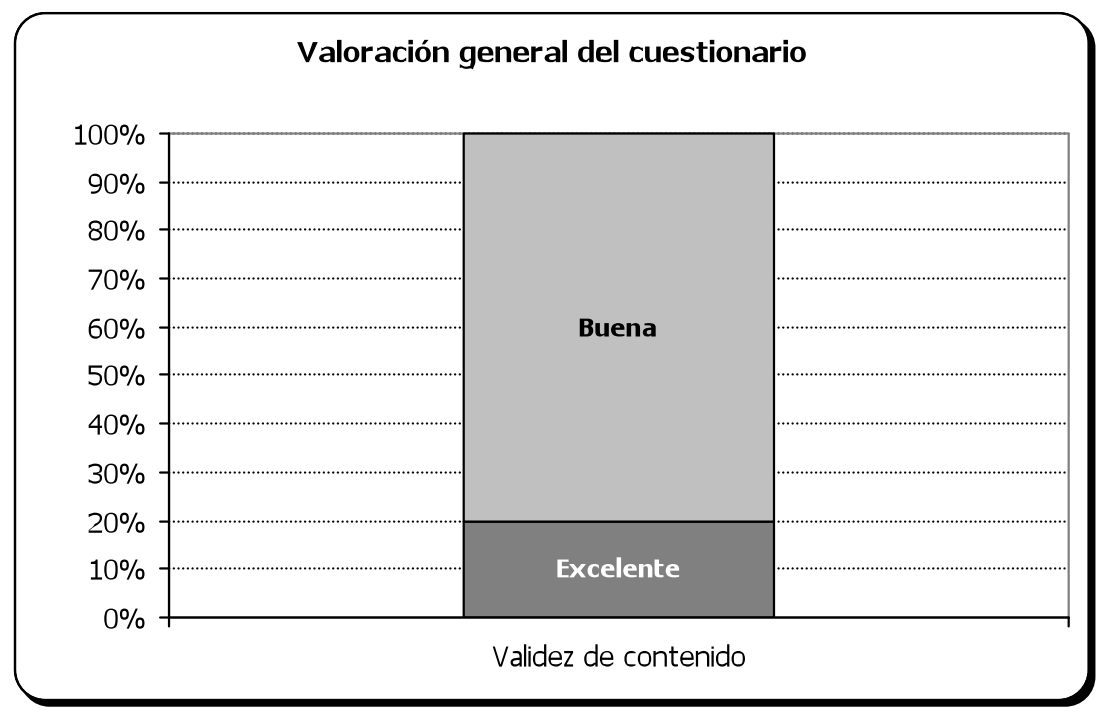

Gráfica 4: Resultados cuantitativos de la validación general del cuestionario por juicio de expertos.

Las calificaciones de los expertos generaron las siguientes medidas de tendencia central: $\bar{x}=$ 3,2 (entre Buena $=3$ y Excelente $=4$ ) con $S(x)=0,4216 ; M_{e}=3,0$ (Buena) y $M_{d}=3,0$ (Buena). De acuerdo con estos resultados, los expertos consideraron que la validez de contenido del cuestionario era buena.

La totalidad de los expertos $(100 \% ; f=10)$ también expresó abiertamente sus opiniones sobre el instrumento en el espacio titulado "Percepción general sobre el cuestionario" y $60 \%(f=6)$ de ellos anotó comentarios adicionales en el espacio titulado "Observaciones y recomendaciones". A continuación se describen esas notas.

1. Percepción general sobre el cuestionario: El análisis de las percepciones generales manifestadas de forma abierta arrojó tres categorías de agrupación para los 
comentarios: Aspectos positivos, limitaciones al emitir el juicio y sugerencias para modificar alguna parte del instrumento.

- Aspectos positivos: La mayoría de los expertos se expresaron usando calificativos que se asocian con una percepción positiva del instrumento. Un ejemplo de estos comentarios se trascribe a continuación: "El cuestionario me pareció muy bien concebido. Claramente expresado y con aparente validez de contenido" (Experto 3).

- Limitaciones al emitir el juicio: Tres expertos mencionaron limitaciones para emitir un juicio terminante. Por ejemplo, el Experto 10 expresó: "El cuestionario es adecuado por lo que puedo percibir sin conocer ni las hipótesis ni el planteamiento del problema. Por ello mi apreciación es limitada".

- Sugerencias para modificar el instrumento: Algunos expertos propusieron modificaciones al cuestionario. Ejemplo de ello es una recomendación del Experto 7: "La redacción de la pregunta 19 no es adecuada, podría ser algo como: '¿Con qué frecuencia proporcionó a los estudiantes retroalimentación sobre las debilidades y progresos en sus aprendizajes?'”.

2. Observaciones y recomendaciones: En general, este espacio fue empleado para expresar buenos deseos en el desarrollo de la investigación o hacer referencia a información ya expresada en otros apartes.

\section{DISCUSIÓN}

Los resultados cuantitativos aportaron información importante sobre la apreciación de los expertos; sin embargo, los aportes más valiosos provinieron de los resultados cualitativos. Todas las sugerencias de los expertos se procesaron, se analizaron y se consideraron para la construcción de la versión final del instrumento. El resumen general de los cambios sugeridos, organizados de acuerdo a las partes que conformaron la guía de validación, puede verse en la figura 1.

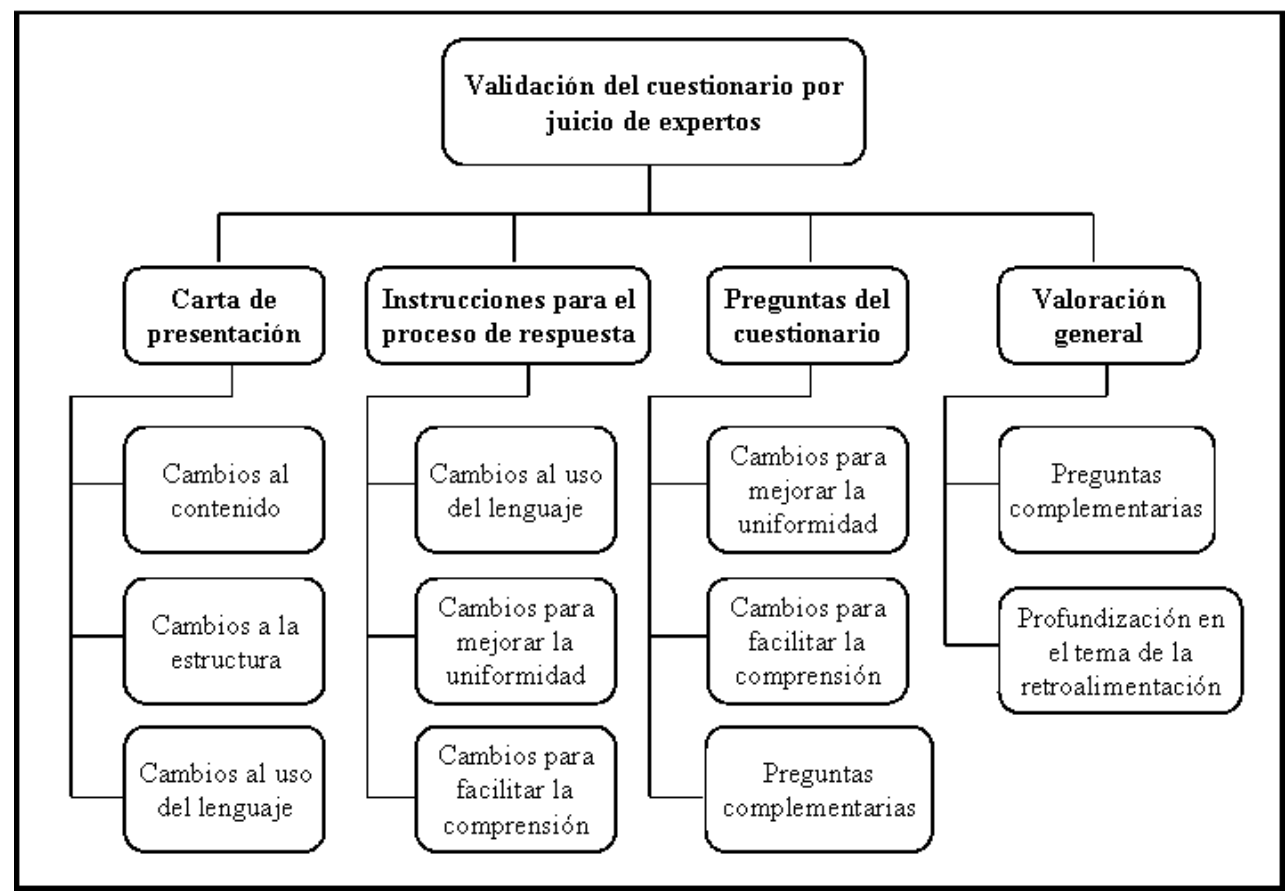

Figura 1: Resumen general de cambios sugeridos por los expertos. 
En el caso de la carta de presentación, se decidió incorporar todas las indicaciones de los expertos para las tres categorías, puesto que agregaban valor a la carta. Sin embargo, al hacerlo se tuvieron presentes dos premisas: (a) no exceder la extensión original de una página y (b) consolidar cuidadosamente los aportes con el fin de mantener la consistencia y la coherencia del texto.

También se incorporó la totalidad de sus sugerencias con respecto a las instrucciones para el proceso de respuesta, con una sola excepción: el Experto 10 consideró que "Las instrucciones podrían ser más sintéticas", pero en la revisión dirigida a atender su recomendación no se encontraron instrucciones que pudieran ser resumidas sin el riesgo de afectar su comprensión.

Los cambios más importantes se produjeron en las preguntas del cuestionario. Por una parte, se hicieron ajustes para mejorar su consonancia y para hacerlas más comprensibles. Esto incluyó modificar o complementar los enunciados de cuatro de ellas y, en un único caso, cambiar la presentación de las opciones de respuesta para recoger información más precisa. Por otro lado, atendiendo a las observaciones de los expertos, se incorporaron nuevas variables, nuevos indicadores y/o nuevas preguntas, es decir, se hicieron modificaciones que tuvieron un impacto significativo en la cantidad, variedad y/o calidad de la información que se recogería. A continuación se describen estos cambios, separados según las dimensiones establecidas en el diseño inicial.

\section{Dimensión I: Perfil del docente.}

Para esta dimensión se incorporaron: una nueva variable, tres nuevos indicadores y cuatro nuevas preguntas. En la figura 2 puede verse el detalle de los cambios de fondo incorporados.

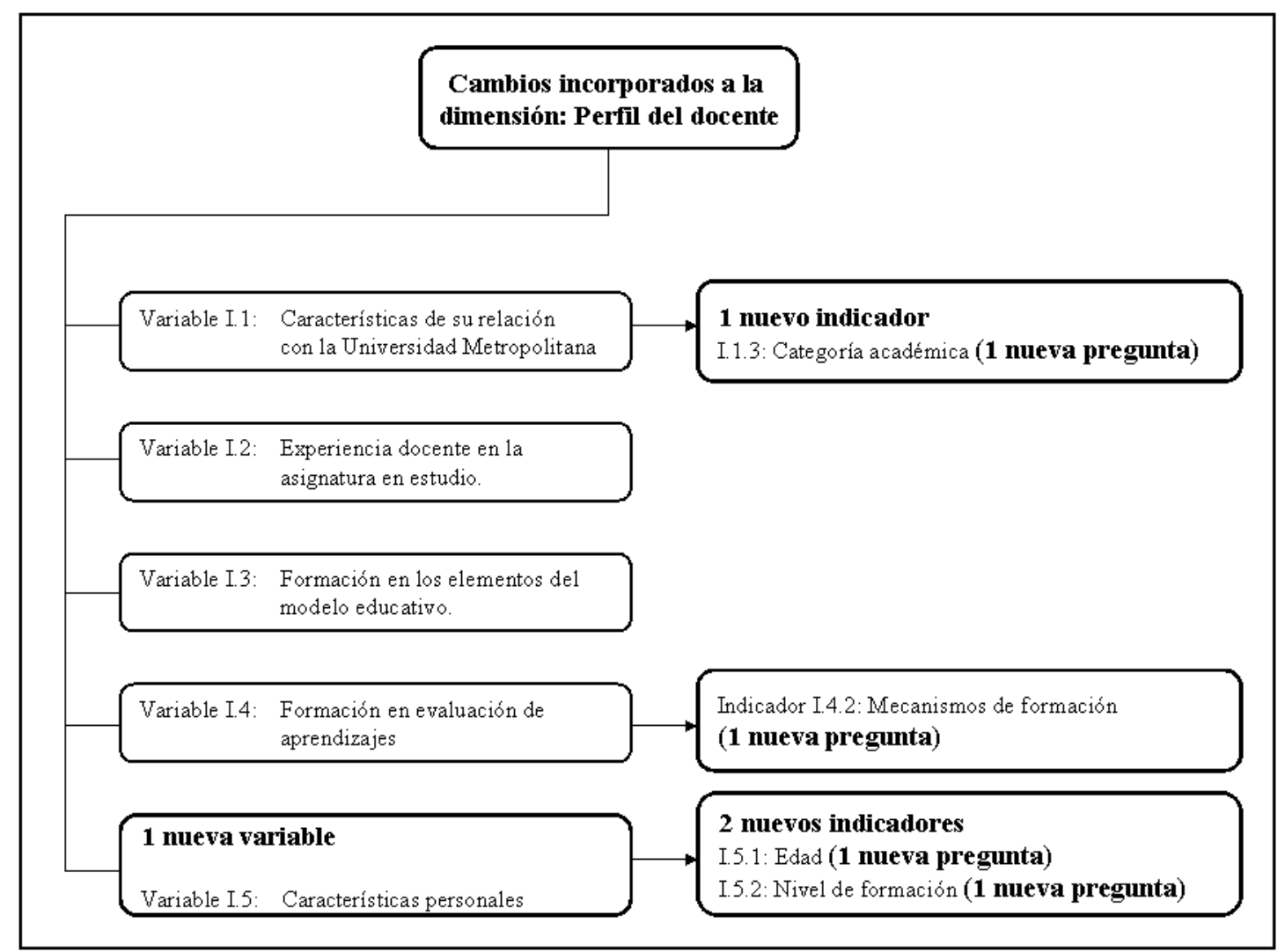

Figura 2: Detalle de los cambios incorporados a la dimensión Perfil del docente. 
Dimensión II: Perfil de la asignatura.

Se sustituyó la variable "Naturaleza de la asignatura" por la variable "Características de la asignatura". Este cambio obedeció a la incorporación de nuevos indicadores que aportaban valor al conocimiento de esta dimensión y que excedían el ámbito de la naturaleza de la asignatura. Dentro de esta variable se incluyeron dos nuevos indicadores y un total de tres nuevas preguntas. En la figura 3 puede verse el detalle de los cambios de fondo incorporados en la dimensión Perfil de la asignatura.

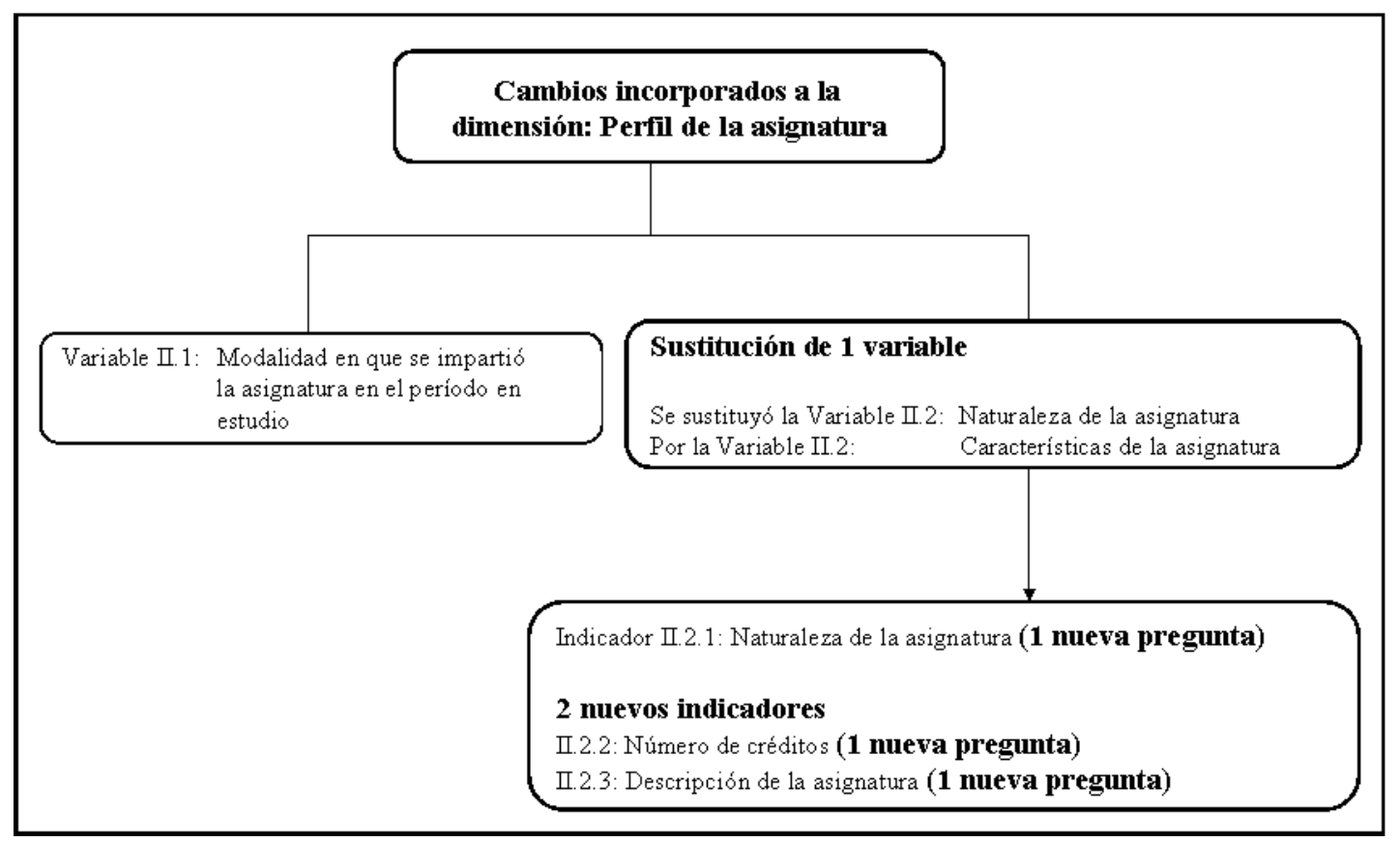

Figura 3: Detalle de los cambios incorporados a la dimensión Perfil de la asignatura.

Dimensión III: Características de la evaluación.

En esta dimensión se mantuvieron las mismas variables consideradas en el diseño inicial, pero se agregaron tres indicadores y cinco nuevas preguntas.

En el caso particular de la variable "Retroalimentación", tratándose de un tema en el que los expertos habían sugerido profundizar, se sustituyó la pregunta única propuesta originalmente por tres que proporcionaran información más precisa y detallada. En la figura 4 puede verse el detalle de los cambios de fondo incorporados en la dimensión Características de la evaluación. 


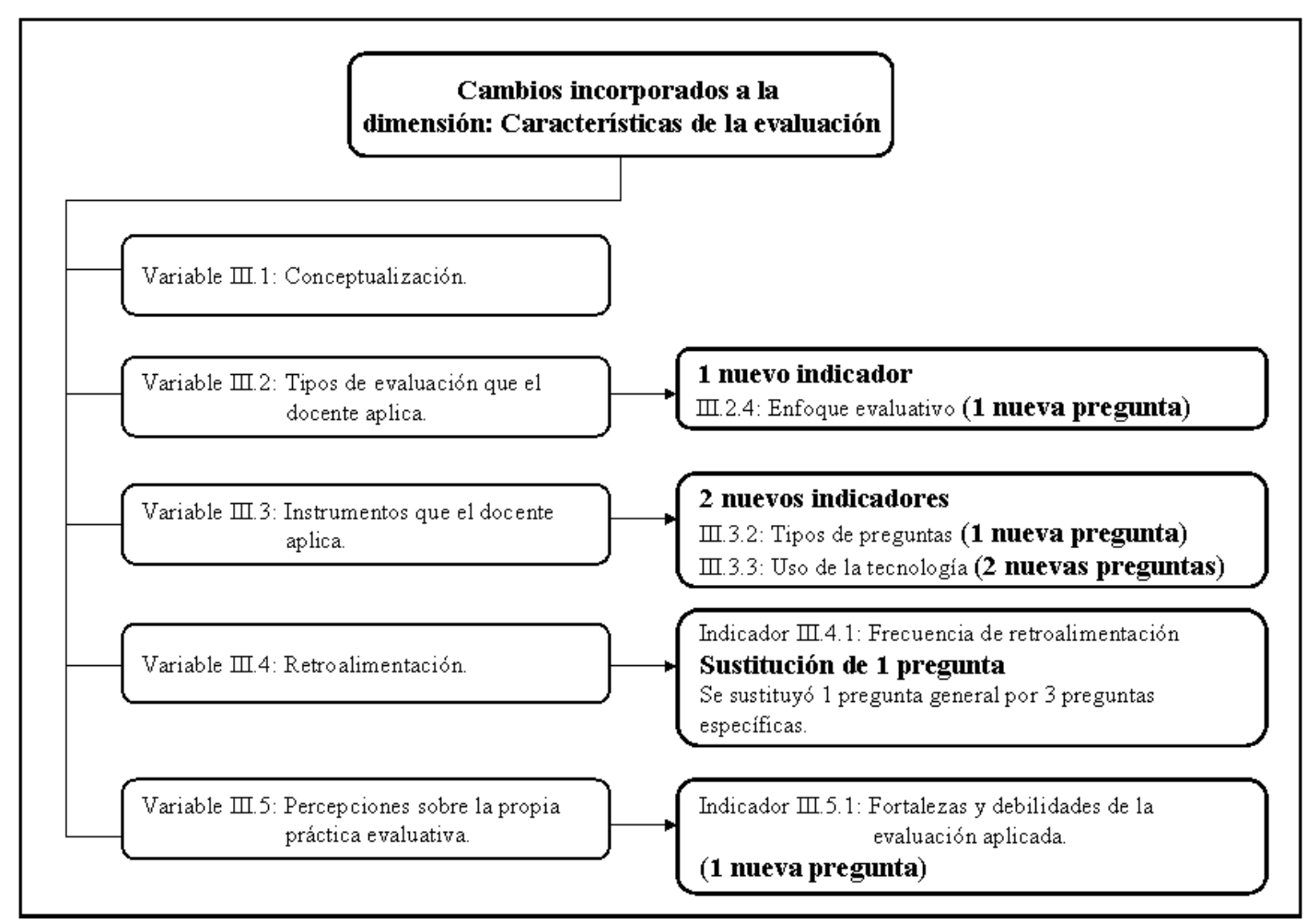

Figura 4: Detalle de los cambios incorporados a la dimensión Características de la evaluación.

La tabla 2 resume la magnitud de los cambios realizados al cuestionario mediante una comparación de las variables, indicadores y preguntas entre sus versiones inicial y final.

\begin{tabular}{|c|l|c|c|}
\hline & Elemento & Versión inicial & Versión final \\
\hline \multirow{3}{*}{$\begin{array}{c}\text { Dimensión I } \\
\text { Perfil del docente }\end{array}$} & Variables & 4 & 5 \\
\cline { 2 - 4 } & Indicadores & 8 & 11 \\
\cline { 2 - 4 } & Preguntas & 8 & 12 \\
\hline \hline \multirow{2}{*}{$\begin{array}{c}\text { Dimensión II } \\
\text { Perfil de la asignatura }\end{array}$} & Variables & 2 & 2 \\
\cline { 2 - 4 } & Indicadores & 2 & 4 \\
\cline { 2 - 4 } & Preguntas & 2 & 5 \\
\hline \hline \multirow{2}{*}{$\begin{array}{c}\text { Dimensión III } \\
\text { eacterísticas de la }\end{array}$} & Variables & 5 & 11 \\
\cline { 2 - 4 } & Indicadores & 8 & 18 \\
\cline { 2 - 4 } & Preguntas & 11 & 12 \\
\hline \hline \multirow{3}{*}{$\begin{array}{c}\text { Total cuestionario } \\
\end{array}$} & Variables & 11 & 26 \\
\cline { 2 - 4 } & Indicadores & 18 & 35 \\
\cline { 2 - 4 } & Preguntas & 21 & 5 \\
\hline
\end{tabular}

Tabla 2: Resumen comparativo entre las versiones inicial y final del cuestionario, en cuanto a los elementos que definen su diseño. 
Siguiendo las clasificaciones propuestas por Buendía (1998: 209-211), la tabla 3 resume la magnitud de los cambios realizados al cuestionario mediante una comparación entre los tipos de preguntas, según la naturaleza de su contenido, en las versiones inicial y final.

\begin{tabular}{|l|c|c|}
\hline $\begin{array}{c}\text { Tipo de pregunta según la } \\
\text { naturaleza de su contenido }\end{array}$ & Versión inicial & Versión final \\
\hline Identificación & 3 & 6 \\
\hline Acción & 4 & 5 \\
\hline Contenido & 8 & 15 \\
\hline Opinión & 3 & 4 \\
\hline Información & 1 & 1 \\
\hline Mixto: Acción y filtro & 1 & 1 \\
\hline Mixto: Información y opinión & 1 & 1 \\
\hline Mixto: Opinión y contenido & 0 & 2 \\
\hline Total preguntas & 21 & 35 \\
\hline
\end{tabular}

Tabla 3: Resumen comparativo entre las versiones inicial y final del cuestionario, en cuanto a los tipos de preguntas según la naturaleza de su contenido.

Siguiendo las categorizaciones propuestas por Buendía (1998: 209-211), la tabla 4 presenta un resumen comparativo entre las versiones inicial y final del cuestionario, en cuanto a los tipos de preguntas según las respuestas que admiten. En particular, el incremento en las preguntas de respuesta abierta permite mayor amplitud en la recolección de datos cualitativos.

\begin{tabular}{|l|c|c|}
\hline $\begin{array}{c}\text { Tipo de pregunta según las } \\
\text { respuestas que admite }\end{array}$ & Versión inicial & Versión final \\
\hline Abierta & 3 & 8 \\
\hline Cerrada & 4 & 6 \\
\hline Categorizada & 10 & 17 \\
\hline Mixta & 4 & 4 \\
\hline \hline Total preguntas & 21 & 35 \\
\hline
\end{tabular}

Tabla 4: Resumen comparativo entre las versiones inicial y final del cuestionario, en cuanto a los tipos de preguntas según las respuestas que admiten.

Cabe destacar dos decisiones que tuvieron impacto significativo en la versión final del cuestionario que se envió al grupo de investigación:

- La elaboración de un glosario de términos, con el propósito de uniformar significados (Ver Anexo 4). Este documento se envió adjunto al cuestionario.

- La reestructuración de las partes que conforman el cuestionario, quedando en la versión definitiva de la siguiente manera:

Parte I: Perfil del docente.

Parte II: Conceptualización de la evaluación de aprendizajes.

Parte III: Perfil de la asignatura.

Parte IV: Características de la evaluación.

En la versión inicial del cuestionario sólo se presentaban tres partes que coincidían exactamente con las dimensiones de investigación, estando la conceptualización de la evaluación de aprendizajes incluida entre las preguntas relacionadas con las 
características de la evaluación. El cambio obedeció a que los hallazgos de un análisis previo de resultados para otro objetivo de investigación revelaron que algunos docentes impartieron dos o más asignaturas pertenecientes a la población, por lo que debían cumplimentar más de un cuestionario. En consecuencia, se decidió modificar la estructura a fin de poder enviar en estos casos un único instrumento en el que respondieran una sola vez las Partes I y II, que son independientes de las asignaturas, pasando luego a responder las Partes III y IV para cada una de las materias a su cargo.

Como producto de los cambios sugeridos por los expertos se reformuló la estructura de variables e indicadores, con el resultado final que se presenta en el Anexo 2.

Una vez reformulada la estructura, se procedió a elaborar el diseño final del instrumento, para lo cual se siguieron las categorizaciones propuestas por Buendía (1998: 209-211). A seguir se elaboró la versión final del instrumento que puede verse en el Anexo 3.

El último paso de esta etapa fue la codificación de las preguntas para su posterior procesamiento. Cabe destacar que estos códigos se crearon exclusivamente para uso del investigador y no se explicitaron en el cuestionario. Las preguntas se presentaron con numeración secuencial para darle al instrumento una apariencia más simple y se organizaron siguiendo un orden lógico que favoreciera la coherencia y facilitara el proceso de respuesta.

\section{REFERENCIAS BIBLIOGRÁFICAS}

AGUADED, J.I. y TIRADO, R. (2010): Ordenadores en los pupitres: informática y telemática en el proceso de enseñanza-aprendizaje en los centros de Andalucía. Pixel-Bit, 34, 205-215.

ALBERT, M.J. (2006): La investigación educativa. Claves teóricas. Madrid, McGraw-Hill.

BLÁZQUEZ, F. y ALONSO, L. (2009): Funciones del profesor de e-learning. Pixel-Bit, 38, 7-21.

BUENDÍA, L. (1998). Técnicas e instrumentos de recogida de datos. En COLÁS, M. y BUENDÍA L. Investigación educativa. Sevilla: Ediciones Alfar, 201-248.

FERNÁNDEZ, C. y otros (2011). Competencias para el aprendizaje en red de los alumnos de educación secundaria en Galicia. Pixel-Bit, 38, 7-21.

GRANDA, A. (2010). Diseño de curso virtual para apoyar el proceso de enseñanza aprendizaje de la disciplina de ingeniería y gestión de software en la universidad de las ciencias informáticas, [artículo en línea]. EDUTEC, Revista Electrónica de Tecnología Educativa. Núm. 34/Diciembre $2010.26 / 01 / 2011]$. http://edutec.rediris.es/revelec2/revelec34

LORENZO, M. y TRUJILLO, J. (2008). Los equipos directivos de educación primaria ante la integración de las TICs. Pixel-Bit, 33, 91-110.

LUKAS, J. y SANTIAGO, K. (2004): Evaluación educativa. Madrid, Alianza Editorial.

MUÑOZ, P. y GONZÁLEZ, M. (2010). Análisis del grado de formación del profesorado de la Universidad de A Coruña en el área de programación y bases de datos bajo sistemas de elearning. Pixel-Bit, 36, 101-114. 
RUIZ, C. (2002). Instrumentos de investigación educativa: Procedimientos para su diseño y validación. Barquisimeto. CIDEG (Centro de Investigación y Desarrollo en Educación y Gerencia).

SÁNCHEZ, C. (2003). Complementariedad metodológica en los proyectos de investigación, en MEDINA, A. y CASTILLO, S. (Coords.). Metodología para la realización de Proyectos de Investigación y Tesis Doctorales. Madrid, Editorial Universitas, 253-264.

\section{Para citar este artículo:}

GARCÍA, E.; CABERO, J. (2011) «Diseño y validación de un cuestionario dirigido a describir la evaluación en procesos de educación a distancia» [artículo en línea]. EDUTEC, Revista Electrónica de Tecnología Educativa. Núm. 35 / Marzo 2011. [Fecha de consulta: dd/mm/aa]. http://edutec.rediris.es/revelec2/revelec35/

ISSN 1135-9250. 
Anexo 1: Guía para la validación por juicio de expertos del cuestionario dirigido a describir la evaluación bajo las modalidades a distancia.

Nombre:

Parte I. Carta de presentación.

\begin{tabular}{|l|l|l|l|l|}
\multicolumn{2}{c|}{} & \multicolumn{3}{c|}{ (Marque con una X su valoración) } \\
\cline { 2 - 5 } \multicolumn{1}{c|}{} & Excelente & Buena & Regular & Mala \\
\hline Claridad de los planteamientos & & & & \\
\hline Adecuación a los destinatarios & & & & \\
\hline Longitud del texto & & & & \\
\hline Calidad del contenido & & & & \\
\hline
\end{tabular}

Modificaciones que haría a la carta de presentación:

Parte II. Instrucciones para el proceso de respuesta.

\begin{tabular}{|l|l|l|l|l|}
\multicolumn{2}{c|}{ (Marque con una X su valoración) } \\
\cline { 2 - 5 } \multicolumn{1}{c|}{} & Excelente & Buena & Regular & Mala \\
\hline Claridad & & & & \\
\hline Adecuación & & & & \\
\hline Cantidad & & & & \\
\hline Calidad & & & & \\
\hline
\end{tabular}

Modificaciones que haría a las instrucciones:

Parte III. Preguntas del cuestionario.

\begin{tabular}{|l|l|l|l|l|}
\multicolumn{2}{c|}{ (Marque con una X su valoración) } \\
\cline { 2 - 5 } \multicolumn{1}{c|}{} & Excelente & Buena & Regular & Mala \\
\hline Orden lógico de presentación & & & & \\
\hline Claridad en la redacción & & & & \\
\hline Adecuación de las opciones de respuesta & & & & \\
\hline Cantidad de preguntas & & & & \\
\hline Adecuación a los destinatarios & & & & \\
\hline Eficacia para proporcionar los datos requeridos & & & & \\
\hline
\end{tabular}

Modificaciones que haría a las preguntas:

Preguntas que agregaría: 
Parte IV. Valoración general del cuestionario.

(Marque con una $X$ su valoración)

Validez de contenido del cuestionario

\begin{tabular}{|l|c|c|c|}
\hline Excelente & Buena & Regular & Mala \\
\hline & & & \\
\hline
\end{tabular}

Percepción general sobre el cuestionario:

Observaciones y recomendaciones:

Gracias por su valioso aporte a nuestra investigación 


\section{Anexo 2: Estructura final de variables e indicadores.}

I. Perfil del docente.

I.1. Características de su relación con la Universidad Metropolitana.

I.1.1. Dedicación docente en la Unimet.

I.1.2. Antigüedad en la Unimet.

I.1.3. Categoría académica en la Unimet.

I.2. Experiencia docente en la asignatura en estudio.

I.2.1. Antigüedad impartiendo la asignatura.

I.3. Formación en los elementos del modelo educativo de la Universidad Metropolitana.

I.3.1. Formación en el modelo AcAd.

I.3.2. Formación en el diseño instruccional DIUM.

1.3.3. Formación en la plataforma PI@tum.

I.4. Formación en evaluación de aprendizajes.

I.4.1. Formación en evaluación de aprendizajes.

1.4.2. Mecanismos de formación.

I.5. Características personales.

I.5.1. Edad.

1.5.2. Nivel de formación.

II. Perfil de la asignatura.

II.1. Modalidad en que se impartió la asignatura durante el período académico en estudio.

II.1.1. Modalidad en que se imparte.

II.2. Características de la asignatura.

II.2.1. Naturaleza de la asignatura.

II.2.2. Número de créditos.

II.2.3. Descripción de la asignatura.

III. Características de la evaluación.

III.1. Conceptualización.

III.1.1. Concepto de evaluación de aprendizajes.

III.1.2. Factores que caracterizan a la evaluación.

III.2. Tipos de evaluación que el docente aplica.

III.2.1. Tipos que aplica según el momento y la frecuencia.

III.2.2. Método que aplica según los agentes evaluadores.

III.2.3. Modalidad de aplicación.

III.2.4. Enfoque evaluativo.

III.3. Instrumentos que el docente aplica.

III.3.1. Instrumentos aplicados.

III.3.2. Tipos de preguntas empleados.

III.3.3. Uso de la tecnología en la evaluación.

III.4. Retroalimentación.

III.4.1. Frecuencia de retroalimentación.

III.5. Percepciones sobre la propia práctica evaluativa.

III.5.1. Fortalezas y debilidades de la evaluación. 
Anexo 3: Versión final del cuestionario dirigido a describir los procesos de evaluación bajo las modalidades a distancia, desde la perspectiva del docente.

\section{Parte I. Perfil del docente.}

1. Indique su edad;

En las siguientes preguntas marque con una X la casilla que exprese su situación actual:

2. Dedicación en la Universidad Metropolitana:

Tiempo parcial
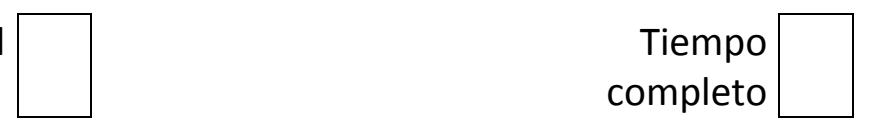

3. Antigüedad como docente en la Universidad Metropolitana:

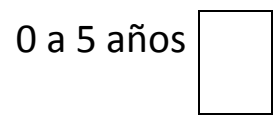

6 a 10 años

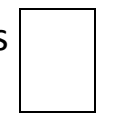

11 a 15 años

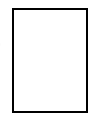

Más de 15

años

4. Categoría académica en la Universidad Metropolitana:

Asistente

Agregado

Asociado

Titular

5. Nivel de formación (Puede marcar más de una casilla):

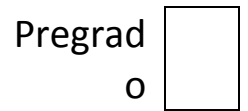

Especialist
$a$
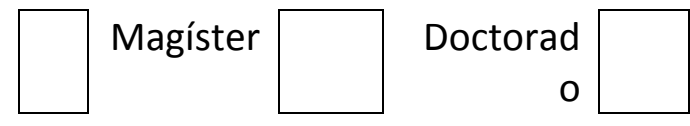

Postdoctorad

o

6. Antigüedad impartiendo esta asignatura (bajo cualquier modalidad) en la Unimet:

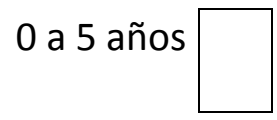

6 a 10 años

11 a 15 años

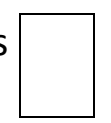

Más de 15

años

7. ¿Ha tomado el taller del Modelo AcAd?

8. ¿Ha tomado el taller del diseño de instrucción DIUM?

9. ¿Ha tomado el taller de la plataforma educativa PI@tum?

10. ¿Se ha formado en evaluación del aprendizaje?
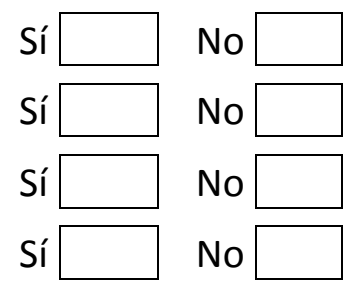

Si respondió negativamente a la pregunta 10, pase directamente a la Parte II.

11. Su formación en el área de la evaluación de aprendizajes la ha logrado a través de: (Puede marcar más de una casilla)

\begin{tabular}{|c|}
\hline Estudio autónomo \\
\hline Educación formal \\
\hline
\end{tabular}

Intercambio con colegas

Talleres y/o cursos
Experiencia

Otros

Si marcó la opción "Otros", por favor especifique:

12. ¿Ha tomado cursos de evaluación en la Universidad Metropolitana:

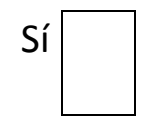

No

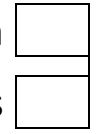




\section{Parte II. Conceptualización de la evaluación de aprendizajes.}

13. En el espacio que se proporciona a continuación, escriba su definición de evaluación de aprendizajes. Para ello exponga con la mayor claridad y exactitud posible el significado que para usted tiene ese concepto, así como la naturaleza y el propósito que usted le atribuye.

14. En las siguientes líneas numeradas escriba en orden de importancia los tres factores que, en su opinión, deben caracterizar a la evaluación de aprendizajes. Para ello siéntase libre de seleccionar y expresar los tres atributos que usted considera determinantes para que la evaluación cumpla adecuadamente su propósito.

(1)

Parte III. Perfil de la asignatura.

Asignatura en estudio: (Nombre y código proporcionado por el investigador).

\section{Período académico en estudio:}

15. Indique el número de créditos que tiene la asignatura:

16. En el espacio que se proporciona a continuación describa la asignatura. Para ello exponga con la mayor claridad y exactitud posible la naturaleza y el propósito que usted le atribuye.

17. Escriba en cada casilla el porcentaje de influencia que, en su opinión, tiene cada uno de los siguientes componentes en la naturaleza de la asignatura:

$$
\text { Teoría } \square \% \quad \text { Práctica } \square \%
$$

18. Marque con una $X$ la casilla que indica la índole de la asignatura:
Depende de la carrera/postgrado

$\square$
Electiva $\square$
No sé $\square$

19. Marque con una $X$ la casilla que indica la modalidad bajo la cual impartió usted la asignatura en el período académico en estudio (Ver glosario anexo):

\begin{tabular}{|c|c|c|}
\hline $\begin{array}{r}\text { Presencial con apoyo } \\
\text { tecnológico }\end{array}$ & Semipresencial & Totalmente a distancia \\
\hline
\end{tabular}




\section{Parte IV. Características de la evaluación.}

20. Marque con una $X$ la(s) casilla(s) que indican los tipos de evaluación que se aplicaron en su asignatura durante el período académico en estudio (Ver glosario anexo).

(a) Evaluación inicial o diagnóstica

(b) Evaluación del proceso o continua

(c) Evaluaciones parciales

(d) Evaluación final

(e) Otra

Si marcó la opción "Otra", por favor especifique:

21. Marque con una $X$ la casilla que corresponda al nivel de autonomía que se le otorgó para decidir el momento y la frecuencia con que se aplicaron las evaluaciones en su asignatura.
Total
Parcial
Ninguna

22. En la siguiente tabla se le presentan tipos de evaluaciones según los agentes evaluadores que participan en el proceso (Ver glosario anexo).

En la columna "Utilizada" marque con una X si utilizó o no el tipo de evaluación.

Para cada tipo utilizado: en la columna "Calificada" marque una X si el tipo de evaluación tuvo impacto en las calificaciones de los estudiantes o si no lo tuvo.

Para cada tipo utilizado y calificado: si el tipo de evaluación tuvo un porcentaje específico en el plan de evaluación, escríbalo en la columna "Porcentaje".

\begin{tabular}{|c|c|c|c|c|c|}
\hline \multirow{2}{*}{ Tipo } & \multicolumn{2}{|c|}{ Utilizada } & \multicolumn{2}{|c|}{ Calificada } & \multirow{2}{*}{ Porcentaje } \\
\hline & Sí & No & Sí & No & \\
\hline (a) Autoevaluación & & & & & \\
\hline (b) Coevaluación & & & & & \\
\hline (c) Evaluación externa o unidireccional & & & & & \\
\hline (d) Evaluación multidireccional & & & & & \\
\hline
\end{tabular}

23. Marque con una $X$ la casilla que corresponda al nivel de autonomía que se le otorgó para decidir la aplicación de evaluaciones con distintos agentes evaluadores.

Total $\square \quad$ Parcial $\square \quad$ Ninguna $\square$


24. Marque con una X la casilla que mejor describe la modalidad de la evaluación en su asignatura durante el período académico en estudio (Ver glosario anexo):
a. Presencial
b. Semipresencial
c. Totalmente a distancia

25. Marque con una $X$ la casilla que corresponda al enfoque con que usted evaluó a sus estudiantes en el período académico en estudio (Ver glosario anexo).
Cuantitativo
Cualitativo
Combinación de ambos

26. En la siguiente tabla se le presentan una serie de actividades que pueden formar parte del proceso de enseñanza-aprendizaje de una asignatura.

No marque ninguna casilla en aquellas actividades que no formaron parte de su programa.

Marque una X en la columna "Presencial" en las actividades que realizó presencialmente.

Marque una $\mathrm{X}$ en la columna "Virtual" en las actividades que realizó a través de medios electrónicos de comunicación.

Marque una $\mathrm{X}$ en la columna "Calificada" en las actividades que tuvieron impacto en las calificaciones de los estudiantes.

Emplee los espacios dejados en blanco para incluir otras actividades que se realizaron en su asignatura.

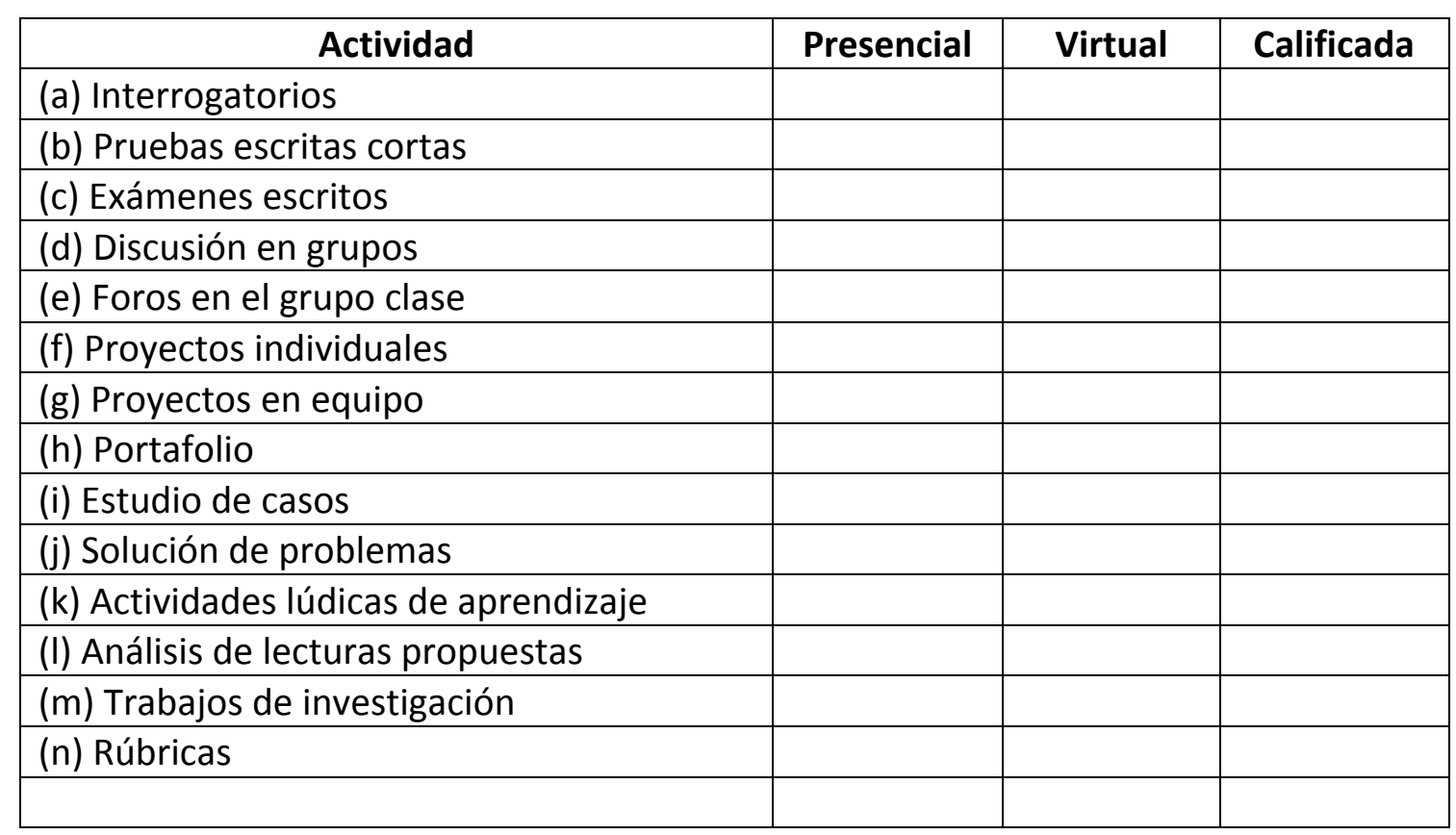


27. Marque con una $X$ la casilla que indica la frecuencia con que incluyó cada uno de los siguientes tipos de preguntas en las actividades que propuso a sus estudiantes.

$\begin{array}{ccc}\text { Nunca } & \begin{array}{c}\text { Algunas } \\ \text { veces }\end{array} & \text { Con } \\ \text { frecuencia } & \text { Siempre }\end{array}$
a. Preguntas de respuesta cerrada.
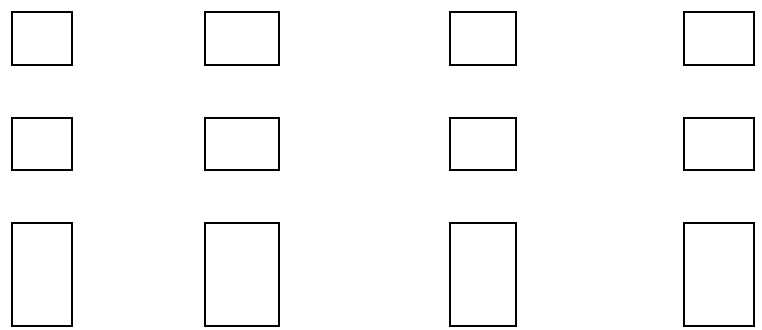
b. Preguntas de respuesta breve.
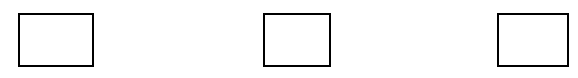
c. Preguntas de respuesta tipo ensayo.
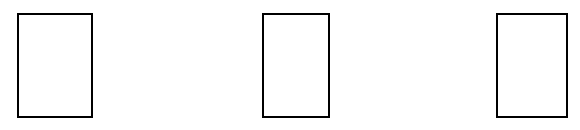
d. Otra

Si marcó la opción "Otra”, por favor especifique:

28. ¿Utilizó usted herramientas tecnológicas como apoyo al proceso de evaluación?

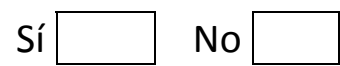

Si respondió negativamente a la pregunta 28, pase directamente a la pregunta 30.

29. En el espacio que se proporciona a continuación, describa el uso que usted le dio a la tecnología como apoyo al proceso de evaluación.

30. Marque con una $X$ la casilla que indica la frecuencia con que usted proporcionó a los estudiantes retroalimentación sobre sus deficiencias o retrasos en el proceso de aprendizaje de la asignatura en general. (Ver glosario anexo)

Nunca $\square$ Continuamente $\square$ Periódicamente $\square$ Ocasionalmente $\square$ Al final $\square$

31. Marque con una $X$ la casilla que indica la frecuencia con que usted proporcionó a los estudiantes retroalimentación sobre sus progresos en el proceso de aprendizaje de la asignatura en general. (Ver glosario anexo)
Nunca
Continuamente
Periódicamente
Ocasionalmente
Al final 
32. Marque con una $X$ la casilla que indica la frecuencia con que usted proporcionó cada uno de los siguientes tipos de retroalimentación a sus estudiantes, en relación con los resultados de las actividades que les asignó. (Ver glosario anexo)

$\begin{array}{ccc}\text { Nunca } & \begin{array}{c}\text { En algunas } \\ \text { actividades }\end{array} & \begin{array}{c}\text { En casi todas } \\ \text { las }\end{array} \\ & \text { actividades } & \end{array}$

a. Les proporcionó la solución correcta.
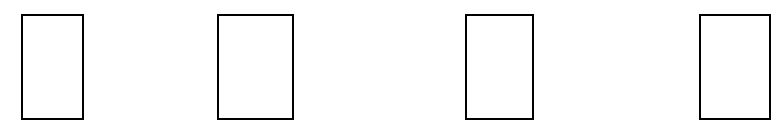

b. Señaló los errores en sus respuestas.
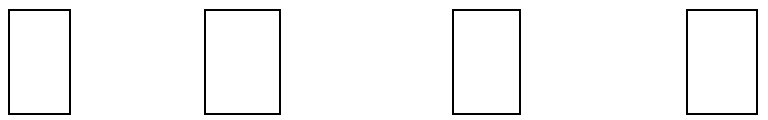

c. Explicó sus deficiencias.
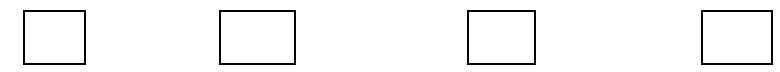

d. Sugirió acciones de mejora.
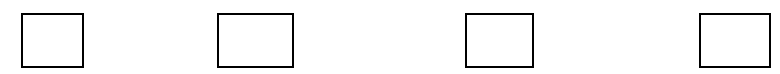

e. Destacó sus progresos.
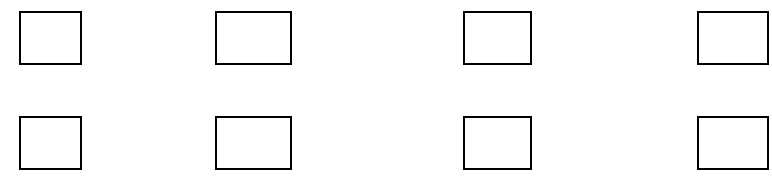

Si marcó la opción "Otra", por favor especifique:

33. En el espacio que se proporciona a continuación, describa las fortalezas que presenta el sistema de evaluación que usted aplicó en su asignatura, entendiendo por fortalezas los atributos de ese sistema que favorecieron que la evaluación cumpliera su propósito.

34. En el espacio que se proporciona a continuación describa las debilidades, si las hubiere, del sistema de evaluación que usted aplicó en su asignatura, entendiendo por debilidades los atributos de ese sistema que limitaron o al menos no favorecieron que la evaluación cumpliera su propósito.

35. En el espacio que se proporciona a continuación, describa alguna(s) propuesta(s) que, en su opinión, mejorarían el proceso de la evaluación de aprendizajes en su asignatura. 
Anexo 4: Glosario de términos adjunto a la versión final del cuestionario dirigido a describir los procesos de evaluación bajo las modalidades a distancia, desde la perspectiva del docente.

Estimado profesor:

A continuación le presento un glosario que puede clarificar la intención de algunos términos o expresiones empleados en el cuestionario anexo. Las definiciones aparecen ordenadas de acuerdo con la numeración de las preguntas a las que corresponden.

Pregunta 19: Modalidades en que se impartió la asignatura.

- Presencial con apoyo tecnológico:

Entendemos que en una asignatura impartida bajo esta modalidad, todas las sesiones de clase ocurren en horarios y en espacios físicos predeterminados, a los que deben asistir tanto el docente como los estudiantes. Sin embargo, la acción educativa se apoya en herramientas tecnológicas con diversos fines entre los que se pueden contar: Disposición permanente de los materiales didácticos, publicación de noticias, consultas a distancia, publicación de actividades (enunciados y/o respuestas), discusiones electrónicas, trabajo colaborativo, evaluaciones, etc.

- Semipresencial:

Entendemos que en una asignatura impartida bajo esta modalidad, algunas sesiones de clase ocurren en horarios y en espacios físicos predeterminados a los que deben asistir tanto el docente como los estudiantes, mientras que otras sesiones ocurren a distancia mediante la aplicación de estrategias didácticas diseñadas para ello y que utilizan las tecnologías para la necesaria interacción entre los estudiantes y de ellos con el profesor.

- Totalmente a distancia:

Entendemos que en una asignatura impartida bajo esta modalidad, todas las sesiones de clase ocurren a distancia mediante la aplicación de estrategias didácticas diseñadas para ello y que utilizan las tecnologías para la necesaria interacción entre los estudiantes y de ellos con el profesor. Esta modalidad puede incluir algunos encuentros presenciales con propósitos específicos, entre los que pueden contarse: Iniciación o cierre de la asignatura y evaluaciones eventuales.

Pregunta 20: Tipos de evaluación según el momento y la frecuencia.

Siguiendo a García Aretio (2002: 292-293) los tipos de evaluación propuestos se definen de la siguiente manera:

- Evaluación inicial o diagnóstica: Se realiza al comienzo del curso y proporciona al docente un panorama de la situación de cada estudiante en particular y del grupo en general.

- Evaluación del proceso o evaluación continua: Se aplica a lo largo del curso y permite, a través de la retroalimentación constante, que la evaluación sea realmente formativa.

- Evaluación final: Se lleva a cabo al final del curso y debería ser consecuencia lógica de la evaluación que se ha venido realizando durante el curso.

Para efectos de este estudio se agregó la categoría "Evaluaciones parciales" para separar los procesos evaluativos caracterizados por la aplicación exclusiva de los instrumentos conocidos en nuestro contexto como exámenes parciales. Aunque puede considerarse que constituyen una forma de evaluación continua, se quiere diferenciar estos esquemas de los que incluyen actividades más variadas y frecuentes. 
Pregunta 22: Tipos de evaluación según los agentes evaluadores que participan en el proceso.

Siguiendo a Fuentes, Chacín y Briceño (2003: 57-59) los tipos de evaluación propuestos se definen de la siguiente manera:

- Autoevaluación: Caracterizada por que cada estudiante evalúa sus propios procesos de aprendizaje.

- Coevaluación: Caracterizada por la participación de los pares en la evaluación de los procesos de aprendizaje del estudiante.

- Evaluación externa o unidireccional: Caracterizada por la emisión de juicio evaluativo por parte del docente o un jurado (criterio de experto).

- Evaluación multidireccional: Caracterizada por la participación de diferentes miembros del grupo en la evaluación del estudiante (docente, invitados externos y el propio estudiante).

Pregunta 24: Modalidades de evaluación.

- Evaluación presencial: Todas las actividades que conforman la evaluación se aplican con la presencia física simultánea del evaluador y del evaluado en el mismo espacio.

- Evaluación semipresencial: Algunas evaluaciones se aplican con la presencia física simultánea del evaluador y del evaluado en el mismo espacio y otras evaluaciones se aplican a distancia.

- Evaluación totalmente a distancia: Todas las actividades que conforman la evaluación se aplican a distancia.

Pregunta 25: Enfoque de la evaluación.

- Enfoque cuantitativo: A través de los instrumentos que aplica mide la cantidad de aprendizajes adquiridos.

- Enfoque cualitativo: A través de los instrumentos que aplica mide la calidad de los aprendizajes adquiridos.

Preguntas 30 a 32: Retroalimentación.

Retroalimentación: Información basada en los resultados de la evaluación y que pretende motivar a los estudiantes a seguir aprendiendo, capacitarlos para corregir sus errores o deficiencias y, en general, orientarlos para enfocar sus actividades de aprendizaje.

Retroalimentación con respecto a la asignatura en general: Se refiere a información basada en los resultados de su valoración general de las deficiencias y/o los progresos de los estudiantes en cuanto a lograr el propósito y los objetivos generales de la asignatura.

Retroalimentación con respecto a las actividades que les asignó: Se refiere a información basada en los resultados de su valoración específica de las respuestas de los estudiantes a las actividades propuestas. 